urgently needed is apparent to all acquainted with the situation. To mention that blowflies live so long as three months; they can fly at least ten miles ; and a single female can produce 2,000 eggs during its life-time, is but to touch the fringe of the problem. The factor, or factors, which cause initial attraction of blowflies to sheep is a question ever confronting those in search of a solution to the problem. "There is evidence," says the report, "that bacterial activity is an important factor predisposing to blowfly attack". This view clearly opens up new avenues of approach in the control of these pests. Particularly significant is the discovery that susceptibility to blowfly attack is an inherent character among merino sheep. "It may be quite definitely stated," continues the report, "that sheep are not struck simply by chance, for the more the subject is studied the stronger becomes the conviction that there must be a definite susceptibility on the part of the sheep and that the liability to strike is fundamentally dependent upon some factor in the sheep itself. . . . Susceptibility in the great majority of cases is primarily due to some inherited character of the individual sheep." The inherent characters, such as conformation of the body, wrinkling of the skin, condition of the wool, are sufficiently apparent to make it possible to group the members of a Merino flock into 'relatively insusceptible', 'moderately susceptible' and 'definitely susceptible' according to their predisposition to blowfly attack.

A real advance has been made by demonstrating that by systematic and selective breeding from sheep in these groups the degree of susceptibility to attack may be markedly reduced. Sheep-owners, particularly of the Merino sheep, will await with particular interest the developments of this line of work. Meanwhile, the report offers much by way of recommendation for direct measures of control. Biological methods, through the introduction of parasites, unfortunately hold out little promise of success. It is recognised, also, that so far as direct measures are concerned, the blowfly pest cannot be combated by any one method alone. The recommendations, therefore, include :-crutching, jetting, surgical operation to remove certain body folds, and systematic trapping of flies with meat rendered attractive for a longer period by special treatment. Finally, when sheep are attacked, the following dressings receive special mention: (a) 5 per cent aqueous solution of zinc sulphate, (b) 5 per cent aqueous solution of 'Monsol', (c) 4 per cent phenol crystals in whale oil.

The report is not only a valuable contribution to the sheep blowfly problem in Australia but will also be welcomed by workers in other countries for its suggestions of methods of approach to the problem as a whole.
W. M. D.

\title{
Natural Woodlands of Great Britain and Ireland
}

A SMALL brochure has been issued by the A Department of Forestry, Oxford, at the instance of Prof. Troup, entitled "The Natural Woodlands of Britain and Ireland" by Dr. Mark L. Anderson, at the time sylvicultural research officer at the Imperial Forestry Institute (Holywell Press, Oxford, 1932). In a preface, Dr. Anderson states that though detailed information exists on this subject in certain parts of the country he had to draw to some extent on his own experience, which, it may be added, is extensive, in order that the general survey should cover the whole of the British Isles. The second part of the work, for which the author assumes entire responsibility, sets forth a classification of waste-land communities, with the view of facilitating choice of tree species in afforestation work.

In his opening remarks, the author points out the difficulty of the study of climax forests in Great Britain and Ireland owing to the widespread destruction of woodlands through the march of agriculture, the spread of the rabbit, and the extensive demand for timber. After indicating the chief and subordinate and indigenous tree species of the British Isles and the more important of the imported trees, the author states that climate and soil have been the main determining factors in deciding the ranges of the various communities. Owing to the wide variation in topography, in geology and soil conditions, which are so marked when contrasted with other and extensive parts of the British Empire, soil must be regarded as of at least equal importance as climate.

The classification of natural woodlands adopted by the author is mainly based on "The Woodlands of England" by Moss, Rankin and Tansley, with the addition of a few communities which are more typically Scottish.

Fifteen main communities have been established, as follows : (1) beechwood association; (2) ashwood community; (3) Ash-alder community; (4) ashbirch community; (5) ash-oakwood community; (6) alder-willow community; (7) moist oakwood association ; (8) dry oakwood communities ; (9) oakbirch community ; (10) alder-birch community ; (11) Scots pine communities; (12) Scots pine-birch community; (13) birch-rowan community; (14) birchaspen community ; (15) birchwood communities.

Of these, the beechwood association has been fairly well studied, the oakwood communities to a lesser extent. The observations on the rest are based on scattered recorded statements and on the author's extensive personal experience.

The second part of the brochure, based, as the author tells us, on his own research work, is entitled "Classification of Waste Land Types". Dr. Anderson points out that during recent years it has become customary to make considerable use of plant communities, found on bare or waste land which is to be afforested, as indicators of the suitability or otherwise of the site for various tree species. Considerable confusion has arisen owing to the fact that the work of numbers of observers has been confined to comparatively restricted localities with the consequent enumeration of too extensive a number of local communities. The author attempts to deal with this matter on broader lines. The term "waste land' is explained as meaning any land available for tree planting which has been devoid of a crop of trees for many years or which has never carried such a crop. In examining, with the view of making use of the vegetation on such an area, a necessary warning is rightly given. Amongst other factors, for example, plant communities will be markedly affected on areas subject to grazing animals (especially sheep and rabbits), moor burning (grouse moors) and other factors. Dr. Anderson recognises five arbitrary degrees of soil fertility, each of the five being further 
sub-divided into three sub-classes based on the supply of moisture available in the soil under normal summer conditions. These sub-classes are termed dry, moist and wet. A combination of these groupings gives a series of fifteen site classes which are named after the predominant plant species which normally occur upon them. He admits that it might be possible to recognise more than five fertility classes but considers that from the forestry point of view no great advantage would be obtained.
After detailing his table of waste-land communities based on his five fertility classes, the author then discusses each in turn, winding up with a useful table of tree species capable of being used on each, indicating the species which are storm-resistant and frost-hardy as compared with the more tender species in these respects. A curious omission in the table is that of the hornbeam, a tree with similar sylvicultural characteristics to the beech, and replacing it in frosty areas.

\section{Sex-Distribution in Thalictrum}

$\mathrm{D}^{\mathrm{n}}$ R. ECKHARD KUHN gives an interesting summary of his recent observations upon the occurrence and behaviour of flowers of different sexes in two North American species of Thalictrum in Die Naturwissenschaften of May 12, 1933.

In Th. polygamum, two types of individuals are found growing together, plants with male flowers only and plants which, apart from an occasional flower in the highest order of the influorescence branch system bearing only stamens, are typically bisexual. The study of a large number of plants showed conclusively that in the male flowers the number of stamens is much larger than in the bisexual flowers, an average of 38-40 compared to 11-12, the frequency curves for the two types practically not overlapping at all. The conclusion would seem to be that the bisexual flowers are to be interpreted as at a stage in the reduction of the androcium on the way to the production of purely female flowers: In the other species studied, $T h$. dasycarpum, the two types of individuals found bear either male flowers or female flowers, though in the latter individuals occasional flowers carry from one to three stamens, sometimes fertile and sometimes in various stages of degeneration.

When the attempt is made to self-pollinate the bisexual flowers of $T h$. polygamum or to cross them with the pollen from the stamens of other bisexual individuals, the yield of seed is very poor, contrasting with a hundred per cent yield of seed when the pollen of male flowers is employed. This led to a further study of the anthers of the bisexual flowers. Their development appears perfectly normal and the full complement of pollen is present, though with a greater variation in size of the grains than in the male flowers. These pollen grains almost fail to germinate in a cane-sugar agar in which the pollen from the male flowers germinates freely. With this difference in behaviour is correlated an extraordinary difference in the structure of the extine, which shows nine of the usual germ pores in the germinating pollen and none at all in the pollen from the bisexual flowers; in the latter, on the rare occasions when pollen tubes were seen, their emergence was preceded by an elongation of the grain and a consequent bursting of the extine.

In Th. dasycarpum the pollen grains from the occasional fertile stamens are similarly free from germ pores. This may be the main factor responsible for a certain physiological further sex differentiation in the flowers of $T h$. polygamum, which superficially are male and bisexual, but behave almost as male and female flowers. On the other hand, genetic factors may be responsible for a still further sterility of the pollen of the hermaphrodite flowers, as in many cases a degeneration of the generative cell has been noted after the original single nucleus of the grain has divided.

\section{Disintegration of Atoms by Protons}

M. L. E. OLIPHANT and Lord Rutherford (Proc. Roy. Soc., A, July) have made a more detailed examination of the disintegration of atoms by protons first observed by Cockeroft and Walton.

The voltages employed were lower than in Cockcroft and Walton's experiments, but the proton streams were much more concentrated. A discharge tube of a special form gave a powerful beam of protons mixed with hydrogen molecular ions. The beam was accelerated by a potential difference of $20,000-200,000$ volts and was passed through a magnetic field. The analysed beam then fell on a target which could readily be exchanged for one of a different material.

The efficiency of disintegration was studied as a function of voltage for a thin film of lithium; disintegration was observed at $40 \mathrm{kv}$. and the efficiency rose less rapidly than an exponential curve at higher voltages. The further discussion of this function is deferred until higher voltages have been used, but the results are not in disagreement with Gamow's theory. Experiments with the molecular ions gave the expected result that these behaved like a pair of protons lightly bound together. Disintegrations were investigated with boron and fluorine. No disintegrations were observed with iron, oxygen, sodium, aluminium, or the heavy elements, gold, lead, bismuth, thallium, uranium or thorium. The disintegrations reported by Cockcroft and Walton from uranium seem to have been due to contamination with a light element; Oliphant and Rutherford have experienced strong contamination with boron from pyrex glass.

Oliphant and Rutherford assume that the disintegration of boron ( ${ }^{11}$ ) occurs by splitting into three $\alpha$-particles after absorption of a proton. The most probable mode of disintegration is supposed to be for the three $\alpha$-particles to escape symmetrically with equal velocities, the probability of other modes diminishing with departure from the symmetrical condition. On this basis, they calculate a range distribution curve for the emitted particles which is in agreement with the curve observed. On this interpretation of the range curve, the energy which becomes available in disintegration is about 9 million volts, while the energy calculated from the masses of the particles is 11 million volts. It is hoped to examine this point later in more detail. 